\title{
Pengaruh BAP (Benzile Amino Purin) dan IAA (Indole Asetic Acid) pada Bunga Krisan Menggunakan Desain Eksperimen Faktorial
}

\author{
ADE IRMA NURWAHIDAH ${ }^{1}$, RENDIE PRASETYO ${ }^{2}$ \\ ${ }^{1}$ Magister Statistika Terapan Universitas Padjadjaran, ${ }^{2}$ Magister Biologi Universitas Soedirman \\ email : ${ }^{1}$ adeirmanurwahidah@gmail.com, 2 rendie.prasetyo@gmail.com
}

\begin{abstract}
ABSTRAK
Krisan merupakan sejenis tumbuhan berbunga yang sering ditanam sebagai tanaman hias pekarangan atau bunga petik. Seiring dengan bertambahnya jumlah penduduk, meningkatnya kesejahteraan masyarakat dan bertambahnya kesadaran masyarakat akan keindahan lingkungan maka kebutuhan akan bunga krisan meningkat. Oleh karena itu untuk memenuhi kebutuhan akan bunga krisan dilakukan melalui kultur jaringan. Salah satu faktor yang dapat mempengaruhi terhadap pembiakan secara teknik kultur jaringan yaitu penambahan zat pengatur tumbuh. Dalam penelitian ini menggunakan zat pengatur tumbuh BAP (Benzile Amino Purin) dan IAA (Indole Asetic Acid). Konsentrasi BAP terdiri 4 taraf yaitu $0 \mu \mathrm{M}, 2,5 \mu \mathrm{M}, 5 \mu \mathrm{M}$, dan 7,5 $\mu \mathrm{M}$ sedangkan konsentrasi IAA terdiri 4 taraf juga yaitu $0 \mu \mathrm{M}, 1 \mu \mathrm{M}, 2 \mu \mathrm{M}$, dan $3 \mu \mathrm{M}$. Tujuan dalam penelitian ini yaitu untuk mengetahui pengaruh zat pengatur tumbuh BAP (Benzile Amino Purin) dan IAA (Indole Asetic Acid) terhadap jumlah daun, jumlah akar, jumlah tunas dan tinggi tanman. Untuk mengetahui tujuan tersebut dilakukan pengujian dengan desain eksperimen faktorial. Hasil uji anava menunjukkan pada jumlah daun hanya konsentrasi zat pengatur tumbuh BAP yang signifikan artinya terdapat perbedaan pengaruh konsentrasi zat pengatur tumbuh BAP terhadap jumlah daun dan konsentrasi BAP yang optimal yaitu 7,5 $\mu \mathrm{M}$. Dari hasil anava pada data jumlah akar menunjukkan zat pengatur tumbuh BAP, IAA, dan interaksi antara zat pengatur tumbuh BAP dan IAA signifikan. Pada uji rentang ganda Duncan menggunakan data jumlah akar menyimpulkan bahwa konsentrasi zat pengatur tumbuh yang baik atau optimal yaitu konsentrasi BAP $0 \mu \mathrm{M}$ dan IAA $3 \mu \mathrm{M}$. Pada uji anava jumlah tunas dang tinggi bunga krisan sama-sama menunjukkan hanya zat pengatur tumbuh BAP yang signifikan dan uji rentang ganda Duncan zat pengatur tumbuh yang optimal terhadap jumlah tunas yaitu konsentrasi BAP $10 \mu \mathrm{M}$ dan terhadap tinggi bunga krisan yaitu konsentrasi BAP $0 \mu \mathrm{M}$.
\end{abstract}

Kata Kunci: BAP (Benzile Amino Purin), IAA (Indole Asetic Acid), Desain Eksperimen Faktorial.

\section{PENDAHULUAN}

Krisan merupakan tanaman hias yang sangat popular baik sebagai bunga potong untuk rangkaian bunga maupun untuk materi dekorasi. Seiring dengan bertambahnya jumlah penduduk, meningkatnya kesejahteraan masyarakat dan bertambahnya kesadaran masyarakat akan keindahan lingkungan maka kebutuhan akan bunga krisan meningkat. Berdasarkan Angka Statistik Produksi Hortikultura Tahun 2016 sebesar 433.100.145 tangkai. Selain untuk memenuhi pasar domestik, krisan juga diekspor baik sebagai bunga potong maupun ekspor benih dalam bentuk stek dengan negara tujuan Jepang, Hongkong, Timur Tengah dan Amerika Serikat. Banyaknya krisan yang diekspor ke luar negeri tentunya meberikan keuntungan bagi perkenomian Indonesia khususnya bagi petani bunga krisan.

Dengan semakin banyaknya peminat krisan baik domestik maupun berbagai mancanegara membuat para produsen harus mampu untuk menyediakan bibit tanaman krisan yang seragam serta bebas penyakit dalam jumlah yang besar dan dalam waktu yang relatif singkat. Oleh karena itu upaya pembiakan melalui teknik kultur jaringan dapat menjadi salah satu alternatif. Salah satu faktor yang dapat mempengaruhi terhadap pembiakan secara teknik kultur jaringan yaitu penambahan zat pengatur tumbuh seperti benzile amino purin, indole asetic acid, auksin dan sitokinin. Manfaat zat pengatur tumbuh untuk memacu pertumbuhan tanaman krisan. 


\section{Ade Irma Nurwahidah, dkk.}

Setiap produsen menginginkan jumlah pertumbuhan yang banyak pada bunga krisan tersebut. Faktor pendukung keberhasilan dalam perbanykan tanaman melalui kultur jaringan salah satunya adalah zat pengatur tumbuh. Dalam zat pengatur tumbuh untuk memberikan jumlah pertumbuhan yang banyak seperti daun, akar, dan memacu tinggi bunga krisan diberikan konsentrasi. Ada beberapa konsentrasi yang diberikan dalam pembiakan secara teknik kultur jaringan. Untuk mengetahui konsentrasi optimum dalam menghasilkan pertumbuhan bunga krisan yang banyak maka dilakukan uji perbandingan pasangan rata-rata perlakuan setelah dilakukan uji anava. Terdapat beberapa metode dalam uji perbandingan pasangan rata-rata perlakuan seperti metode Beda Nyata Terkecil (BNT), uji Newman-Keuls, uji Rentang Ganda Duncan, uji Tukey, metode Bonferroni, metode Fisher dan metode Hsu. Dalam penelitian ini akan menggunakan uji rentang ganda Duncan.

\section{KAJIAN PUSTAKA}

\section{DESAIN EKSPERIMEN}

Desain eksperimen yaitu percobaan yang dilakukan untuk mempelajari atau menemukan sesuatu mengenai proses yang ada atau membandingkan efek dari beberapa kondisi terhadap suatu fenomena (Montgomery, 2009). Menurut Suwanda (2011) tujuan yang dicapai dari desain eksperimen adalah untuk memperoleh atau mengumpulkan informasi yang sebanyakbanyaknya yang diperlukan dan berguna dalam melakukan penyelidikan persoalan yang akan dibahas. Meskipun demikian, dalam rangka usaha mendapatkan semua informasi yang berguna, hendaknya desain dibuat sesederhana mungkin. Prinsip dasar dari perancangan percobaan adalah pengulangan (reflication), pengacakan (randomization), dan pengendalian local (local control). Prinsip ini diperlukan untuk pendugaan yang valid dari galat percobaan dan usaha meminimumkan galat percobaan guna meningkatkan ketelitian percobaan.

\section{DESAIN EKSPERIMEN FAKTORIAL}

Desain eksperimen faktorial adalah eksperimen yang semua (hampir semua) taraf sebuah faktor tertentu dikombinasikan atau disilangkan dengan semua (hampir semua) taraf tiap faktor lainnya yang ada dalam eksperimen itu. Berdasarkan adanya banyak taraf dalam tiap faktor, eksperimen ini sering diberi nama dengan menambahkan perkalian antara banyak taraf faktor yang satu dengan yang lainnya. Misalnya, apabila dalam eksperimen digunakan dua buah faktor, satu faktor terdiri dari empat taraf dan satu faktor lagi terdiri atas tiga taraf, maka diperoleh eksperimen factorial 4 × 3 sehingga diperlukan 12 kondisi eksperimen (atau sering pula disebut kombinais perlakuan) yang berbeda-beda. Desain faktorial ini desain yang paling efisien untuk menyelidiki efek dua atau lebih faktor. Dalam desian faktorial, pada setiap replikasi haruslah mengandung semua kombinasi perlaukan. Contoh jika terdapat dua faktor, faktor A dengan a taraf dan faktor B dengan b taraf, maka pada setiap replikasi harus mengandung ab kombinasi perlakuan. Model desain faktorial dalam desain acak lengkap adalah

$$
\begin{gathered}
Y_{i j k}=\mu+A_{i}+B_{j}+(A B)_{i j}+\varepsilon_{i j k} \\
\text { Dengan } \mathrm{i}=1,2, \ldots ., \mathrm{a} \\
\mathrm{j}=1,2, \ldots ., \mathrm{b} \\
\mathrm{k}=1,2, \ldots, \mathrm{n}
\end{gathered}
$$

Keterangan:

$$
\begin{array}{ll}
Y_{i j k} & =\text { Nilai respon untuk taraf } \mathrm{i} \text { faktor } \mathrm{A}, \text { taraf } \mathrm{j} \text { faktor B pada ulangan ke-k } \\
\mu & =\text { Rata-rata yang sebenarnya } \\
A_{i} & =\text { Efek taraf ke-i dari faktor A } \\
B_{j} & =\text { Efek taraf ke-j dari faktor B } \\
(A B)_{i j} & =\text { Efek interaksi taraf ke-i faktor A dan taraf ke-j faktor B }
\end{array}
$$


$\varepsilon_{i j k} \quad=$ Efek kekeliruan acak pada taraf ke-i faktor A, taraf ke-j faktor B dan ulangan ke-k

Dalam pengujian desain faktorial dua faktor, terdapat beberapa rumus yang digunakan untuk menghitung efek tiap faktor dan interaksinya. Rumus-rumus tersebutdisajikan dalam tabel analisis varians sebagaimana tersaji dalam Tabel 1.

Tabe1 1. Anava untuk Eksperimen Faktorial Dua Faktor

\begin{tabular}{|l|c|c|l|l|}
\hline \multicolumn{1}{|c|}{ Sumber Variasi } & $\begin{array}{c}\text { Derajat } \\
\text { Bebas }\end{array}$ & $\begin{array}{c}\text { Jumlah } \\
\text { Kuadrat }\end{array}$ & \multicolumn{1}{|c|}{ Kuadrat Tengah } & F \\
\hline Faktor A & $a-1$ & $J K A$ & $K T A=J K A /(a-1)$ & $K T A / K T E$ \\
\hline Faktor B & $b-1$ & $J K B$ & $K T A=J K B /(b-1)$ & $K T B / K T E$ \\
\hline Interaksi AB & $(a-1) x(b-1)$ & $J K A B$ & $K T A B=J K A B /(a-1)(b-1)$ & $K T A B / K T E$ \\
\hline Kekeliruan & $a b(n-1)$ & $J K E$ & $K T E=J K E / a b(n-1)$ & \\
\hline Total & $a b n-1$ & $J K T$ & & \\
\hline
\end{tabular}

dengan:

Jumlah kuadrat terkoreksi $J K T=\sum_{i=1}^{a} \sum_{j=1}^{b} \sum_{k=1}^{n} y_{i j k}^{2}-\frac{y_{\ldots}^{2}}{a b n}$

Jumlah kuadrat faktor A $J K A=\frac{1}{b n} \sum_{i=1}^{a} y_{i . .}^{2}-\frac{y_{\ldots}^{2}}{a b n}$

Jumlah kuadrat faktor B $J K B=\frac{1}{a n} \sum_{j=1}^{b} y_{. j .}^{2}-\frac{y_{\ldots}^{2}}{a b n}$

Jumlah kuadrat interaksi $J K A B=J K_{\text {subtotal }}-J K A-J K B$

dimana $K_{\text {subtotal }}=\frac{1}{n} \sum_{i=1}^{a} \sum_{j=1}^{b} y_{i j .}^{2}-\frac{y_{\ldots}^{2}}{a b n}$

Jumlah kuadrat kekeliruan $J K E=J K T-J K A-J K B-J K A B$

\section{PERBANDINAGAN PASANGAN RATA-RATA PERLAKUAN}

Apabila hasil pengujian dengan anava ternyata signifikan (untuk model tetap), maka untuk mengetahui rata-rata taraf perlakuan mana yang berbeda dapat digunakan uji rata-rata taraf perlakuan mana yang berbeda dapat digunakan uji rata-rata sesudah anava. Uji rentang ganda Duncan merupakan salah satu metode yang digunakan untuk melakukan uji perbandingan pasangan rata-rata perlakuan.

1. Uji Rentang Ganda Duncan

Uji ini dibuat oleh Duncan (1955), prosedur pengujiannya sama dengan uji Newman-Keuls. Duncan merumuskan simpangan baku rata-rata perlakuan sebagai berikut:

$$
S_{\bar{y}_{i}}=\sqrt{\frac{K T E}{n}} \quad ; \mathrm{i}=1,2, \ldots, \mathrm{k}
$$

Jika banyaknya ulangan tiap perlakuan berbeda, $\mathrm{n}$ ditaksir oleh rata-rata harmonis $n_{h}$ yaitu

$$
n_{h}=\frac{k}{\sum_{i=}^{k}\left(1 / n_{i}\right)}
$$

Rentang nyata terkecilnya adalah 
134 Ade Irma Nurwahidah, dkk.

$R_{p}=r_{\alpha(p, f)} S_{\bar{y}_{i}} ; \mathrm{p}=2,3, \ldots, \mathrm{k}$

Dengan $r_{\alpha(p, f)}, \mathrm{p}=2,3, \ldots, \mathrm{k}$ diperoleh dari tabel rentang Duncan pada taraf nyata dan derajat bebas $\mathrm{f}$ (db kekeliruan)

\section{KULTUR JARINGAN}

Pada tahun 1980 kultur jaringan mulai berkembang di Indonesia. Selama lima tahun tersebut penelitian difokuskan pada perbanyakan tanaman. Selanjutnya kultur jaringan diaplikasikan untuk penyimpanan plasma nutfah dan perbaikan tanaman. Saat ini aplikasi kultur jaringan sudah menjadi kegiatan rutin untuk perbanyakan beberapa tanaman kehutanan dan perkebunan. Aplikasi kultur jaringan sangat terkait dengan perkembangan bioteknologi modern. Dampak yang nyata terlihat dengan adanya peningkatan kualitas dan produksi pada komoditas pertanian. Beberapa kegunaan teknologi kultur jaringan yang dapat menunjang perkembangan pertanian yaitu perbanyakan tanaman, perbaikan tanaman, pelestarian plasma nutfah, dan produksi metabolit sekunder.

Banyak faktor yang menentukan keberhasilan dalam pembiakan tanaman melalui kultur jaringan salah satunya yaitu zat pengatur tumbuh (Lestari,2008). Jenis dan konsentrasi zat pengatur tumbuh (ZPT) yang ditambahkan kedalam media kultur sangat berpengaruh terhadap kemamapuan regenerasi tunas. Hormon (zat pengatur tumbuh) tanaman memegang peran penting di dalam mengendalikan pertumbuhan dan perkembangan tanaman, yaitu antara lain mengatur kecepatan pertumbuhan dari bagian-bagian individu dan mengintegrasi bagianbagian ini guna menghasilkan bentuk yang kita kenal sebagai tanaman.

\section{METODE PENELITIAN}

\section{SUMBER DATA}

Dalam penelitian ini menggunakan data eksperimen dari Laboratorium Botani Universitas Soedirman yang dilakukan pada bulan Maret tahun 2016. Penelitian ini dilakukan dengan menggunkan desain faktorial dengan dua faktor yaitu konsentrasi zat pengatur tumbuh BAP (Benzile Amino Purin) dan IAA (Indole Asetic Acid). Konsentrasi BAP terdiri 4 taraf yaitu $0 \mu \mathrm{M}$, $2,5 \mu \mathrm{M}, 5 \mu \mathrm{M}$, dan 7,5 $\mu \mathrm{M}$ sedangkan konsentrasi IAA terdiri 4 taraf juga yaitu $0 \mu \mathrm{M}, 1 \mu \mathrm{M}, 2$ $\mu \mathrm{M}$, dan $3 \mu \mathrm{M}$ sehingga terdapat 16 kombinasi perlakuan. Setiap perlakuan diulang sebanyak 5 kali sehingga terdapat 80 satuan percobaan.

\section{METODE ANALISIS}

Adapun langkah-langkah untuk melakukan penelitian adalah sebagai berikut:

1) Membuat perhitungan anava

2) Menguji pengujian untuk masing-masing faktor A, faktor B atau waktu pengamatan serta interaksi keduanya apakah mempunyai pengaruh terhadap respon yang diamati.

3) Jika kesimpulan yang diambil adalah signifikan maka dilakukan uji rentang ganda Duncan.

\section{HASIL DAN PEMBAHASAN}

\section{JUMLAH DAUN}

Dibawah ini tabel hasil uji anava untuk mengetahui pengaruh konsentrasi zat pengatur tumbuh BAP dan IAA terhadap jumlah daun. 
Tabel 2. Hasil Uji Anava Data Jumlah Daun

\begin{tabular}{|l|c|c|c|c|c|}
\hline \multicolumn{1}{|c|}{$\begin{array}{c}\text { Sumber } \\
\text { Variasi }\end{array}$} & $\begin{array}{c}\text { Derajat } \\
\text { Bebas }\end{array}$ & Jumlah Kuadrat & Kuadrat Tengah & $\boldsymbol{F}$ & P-Value \\
\hline BAP & 3 & 22638.850 & 7546.283 & 18.324 & 0.000 \\
\hline IAA & 3 & 1059.450 & 353.150 & 0.858 & 0.468 \\
\hline $\begin{array}{l}\text { Interaksi BAP } \\
\text { dan IAA }\end{array}$ & 9 & 9734.450 & 1081.61 & 2.626 & 0.012 \\
\hline Kekeliruan & 64 & 26356.800 & 411.825 & & \\
\hline Total & 79 & 59789.550 & & & \\
\hline
\end{tabular}

Dari hasil uji anava pada tabel 2, dengan resiko kekeliruan 5\% dapat diketahui bahwa hanya konsentrasi zat pengatur tumbuh BAP yang signifikan sehingga dapat disimpulkan terdapat perbedaan pengaruh konsentrasi zat pengatur tumbuh BAP terhadap jumlah daun. Selanjutnya, melakukan uji perbandingan ganda menggunakan uji Duncan. Uji perbandingan ganda ini bertujuan untuk mengetahui konsentrasi zat pengatur tumbuh mana yang memberikan hasil optimal pada BAP untuk jumlah daun pada bunga krisan.

Tabe1 3. Uji Duncan untuk Konsentrasi BAP

\begin{tabular}{|l|c|c|c|}
\hline \multirow{2}{*}{ Konsentrasi BAP } & \multirow{2}{*}{$\begin{array}{l}\text { Ukuran } \\
\text { Sampel }\end{array}$} & \multicolumn{2}{|c|}{ Subset } \\
\cline { 3 - 4 } & 20 & 16.200 & $\mathbf{2}$ \\
\hline $0 \mu \mathrm{M}$ & 20 & & 44.750 \\
\hline $2,5 \mu \mathrm{M}$ & 20 & & 56.750 \\
\hline $5 \mu \mathrm{M}$ & 20 & & 58.000 \\
\hline $7,5 \mu \mathrm{M}$ & & & \\
\hline
\end{tabular}

Dari tabel 3 diatas konsentrasi BAP $0 \mu \mathrm{M}$ meberikan pengaruh yang berbeda dengan konsentrasi BAP lainnya yaitu $2,5 \mu \mathrm{M}, 5 \mu \mathrm{M}$, dan $7,5 \mu \mathrm{M}$ terhadap jumlah daun dan konsentrasi BAP 2,5 $\mu \mathrm{M}, 5 \mu \mathrm{M}$, dan $7,5 \mu \mathrm{M}$ memberikan pengaruh yang sama terhadap jumlah daun pada bunga krisan. Dari hasil uji perbandingan ganda Duncan didapatkan konsentrasi zat pengatur tumbuh yang optimal terhadap jumlah daun yaitu konsentrasi BAP 8,5 $\mu \mathrm{M}$.

\section{JUMLAH AKAR}

Dibawah ini tabel hasil uji anava untuk mengetahui pengaruh konsentrasi zat pengatur tumbuh BAP dan IAA terhadap jumlah akar.

Tabel 4. Hasil Uji Anava Data Jumlah Akar

\begin{tabular}{|l|c|c|c|c|c|}
\hline $\begin{array}{c}\text { Sumber } \\
\text { Variasi }\end{array}$ & $\begin{array}{c}\text { Derajat } \\
\text { Bebas }\end{array}$ & $\begin{array}{c}\text { Jumlah } \\
\text { Kuadrat }\end{array}$ & $\begin{array}{c}\text { Kuadrat } \\
\text { Tengah }\end{array}$ & $\boldsymbol{F}$ & P-Value \\
\hline BAP & 3 & 936.450 & 312.150 & 68.510 & 0.000 \\
\hline IAA & 3 & 57.750 & 19.250 & 4.225 & 0.009 \\
\hline $\begin{array}{l}\text { Interaksi BAP } \\
\text { dan IAA }\end{array}$ & 9 & 174.150 & 19.350 & 4.247 & 0.000 \\
\hline Kekeliruan & 64 & 291.600 & 4.556 & & \\
\hline Total & 79 & 1788.000 & & & \\
\hline
\end{tabular}

Dari hasil uji ANOVA pada tabel 4, dengan resiko kekeliruan 5\% dapat diketahui bahwa konsentrasi zat pengatur tumbuh BAP dan IAA signifikan sehingga dapat disimpulkan terdapat 
136 Ade Irma Nurwahidah, dkk.

perbedaan pengaruh konsentrasi zat pengatur tumbuh BAP dan IAA terhadap jumlah akar. Untuk resiko kekeliruan 5\% hasil uji interaksi antara BAP dan IAA juga signifikan yang artinya terdapat interaksi antara konsentrasi zat pengatur tumbuh BAP dan IAA terhadap jumlah akar pada bunga krisan. Selanjutnya, melakukan uji perbandingan ganda menggunakan uji Duncan. Uji perbandingan ganda ini bertujuan untuk mengetahui konsentrasi zat pengatur tumbuh mana yang memberikan hasil optimal atau baik pada BAP dan IAA untuk jumlah akar pada bunga krisan.

Tabel 5. Uji Duncan untuk Konsentrasi BAP

\begin{tabular}{|l|c|c|c|}
\hline \multirow{2}{*}{ Konsentrasi BAP } & \multirow{2}{*}{$\begin{array}{l}\text { Ukuran } \\
\text { Sampel }\end{array}$} & \multicolumn{2}{|c|}{ Subset } \\
\cline { 3 - 4 } & & $\mathbf{1}$ & $\mathbf{2}$ \\
\hline $5 \mu \mathrm{M}$ & 20 & 0.000 & \\
\hline $7,5 \mu \mathrm{M}$ & 20 & 0.000 & \\
\hline $2,5 \mu \mathrm{M}$ & 20 & 0.150 & \\
\hline $0 \mu \mathrm{M}$ & 20 & & 7.950 \\
\hline
\end{tabular}

Dari tabel 5 diatas konsentrasi BAP $5 \mu \mathrm{M}, 7,5 \mu \mathrm{M}$, dan 2,5 $\mu \mathrm{M}$ memberikan pengaruh yang sama terhadap hasil akar tetapi berbeda dengan konsentrasi BAP $0 \mu \mathrm{M}$. Dari hasil uji perbandingan ganda Duncan didapatkan konsentrasi zat pengatur tumbuh yang baik terhadap jumlah akar yaitu konsentrasi BAP $0 \mu \mathrm{M}$.

Tabel 6. Uji Perbandingan Ganda Duncan untuk Konsentrasi IAA

\begin{tabular}{|l|c|c|c|}
\hline \multirow{2}{*}{ Konsentrasi IAA } & \multirow{2}{*}{$\begin{array}{l}\text { Ukuran } \\
\text { Sampel }\end{array}$} & \multicolumn{2}{|c|}{ Subset } \\
\cline { 3 - 4 } & 20 & 0.800 & $\mathbf{2}$ \\
\hline $1 \mu \mathrm{M}$ & 20 & 2.000 & 2.000 \\
\hline $2 \mu \mathrm{M}$ & 20 & 2.100 & 2.100 \\
\hline $0 \mu \mathrm{M}$ & 20 & & 3.200 \\
\hline $3 \mu \mathrm{M}$ & & & \\
\hline
\end{tabular}

Hasil uji pernadingan gandan Duncan untuk konsentrasi IAA pada tabel 3 bahwa konsentrasi IAA $1 \mu \mathrm{M}$. $2 \mu \mathrm{M}$, dan $0 \mu \mathrm{M}$ memberikan pengaruh yang sama tetapi konsentrasi IAA $1 \mu \mathrm{M}$ berbeda dengan konsetrasi $3 \mu \mathrm{M}$. Konsentrasi $2 \mu \mathrm{M}, 0 \mu \mathrm{M}$, dan $3 \mu \mathrm{M}$ memberikan pengaruh yang sama terhadap jumlah akar pada bunga krisan. Pada konsentrasi IAA yang memberikan hasil yang optimal terhadap jumlah akar yaitu pada konsentrasi $3 \mu \mathrm{M}$.

\section{JUMLAH TUNAS}

Dibawah ini tabel hasil uji anava untuk mengetahui pengaruh konsentrasi zat pengatur tumbuh BAP dan IAA terhadap jumlah tunas.

Tabel 7. Hasil Uji Anava Data Jumlah Tunas

\begin{tabular}{|l|c|c|c|c|c|}
\hline Sumber Variasi & $\begin{array}{c}\text { Derajat } \\
\text { Bebas }\end{array}$ & $\begin{array}{c}\text { Jumlah } \\
\text { Kuadrat }\end{array}$ & $\begin{array}{c}\text { Kuadrat } \\
\text { Tengah }\end{array}$ & $F$ & P-Value \\
\hline BAP & 3 & 529.750 & 176.583 & 24.314 & 0.000 \\
\hline IAA & 3 & 10.050 & 3.350 & 0.461 & 0.710 \\
\hline $\begin{array}{l}\text { Interaksi BAP } \\
\text { dan IAA }\end{array}$ & 9 & 115.350 & 12.817 & 1.765 & 0.093 \\
\hline Kekeliruan & 64 & 464.800 & 7.263 & & \\
\hline Total & 79 & 3518.000 & & & \\
\hline
\end{tabular}


Dari hasil uji Anava pada tabel 7, dengan resiko kekeliruan 5\% dapat diketahui bahwa hanya konsentrasi zat penagtur tumbuh BAP yang signifikan sehingga dapat disimpulkan terdapat perbedaan pengaruh konsentrasi zat pengatur tumbuh BAP terhadap jumlah tunas pada bunga krisan. Selanjutnya, melakukan uji perbandingan ganda menggunakan uji Duncan. Uji perbandingan ganda ini bertujuan untuk mengetahui konsentrasi zat pengatur tumbuh mana yang memberikan hasil optimal pada BAP untuk jumlah tunas pada bunga krisan.

Tabel 8. Uji Duncan untuk Konsentrasi BAP

\begin{tabular}{|l|c|c|c|}
\hline \multirow{2}{*}{ Konsentrasi BAP } & \multirow{2}{*}{$\begin{array}{c}\text { Ukuran } \\
\text { Sampel }\end{array}$} & \multicolumn{2}{|c|}{ Subset } \\
\cline { 3 - 4 } & & $\mathbf{1}$ & $\mathbf{2}$ \\
\hline $0 \mu \mathrm{M}$ & 20 & 1.050 & \\
\hline $2,5 \mu \mathrm{M}$ & 20 & & 6.450 \\
\hline $7,5 \mu \mathrm{M}$ & 20 & & 7.150 \\
\hline $5 \mu \mathrm{M}$ & 20 & & 7.250 \\
\hline
\end{tabular}

Dari tabel 8 diatas konsentrasi BAP $0 \mu \mathrm{M}$ meberikan pengaruh yang berbeda dengan konsentrasi BAP lainnya yaitu 2,5 $\mu \mathrm{M}, 7,5 \mu \mathrm{M}$, dan $5 \mu \mathrm{M}$ terhadap jumlah daun dan konsentrasi BAP $5 \mu \mathrm{M}, 15 \mu \mathrm{M}$, dan $10 \mu \mathrm{M}$ memberikan pengaruh yang sama terhadap jumlah daun pada bunga krisan. Dari hasil uji perbandingan ganda Duncan didapatkan konsentrasi zat pengatur tumbuh yang optimal terhadap jumlah tunas yaitu konsentrasi BAP $5 \mu \mathrm{M}$.

\section{TINGGI TANAMAN}

Dibawah ini tabel hasil uji Anava untuk mengetahui pengaruh konsentrasi zat pengatur tumbuh BAP dan IAA terhadap tinggi.

Tabe1 9. Hasil Uji Anava Data Tinggi

\begin{tabular}{|l|c|c|c|c|c|}
\hline \multicolumn{1}{|c|}{$\begin{array}{c}\text { Sumber } \\
\text { Variasi }\end{array}$} & $\begin{array}{c}\text { Derajat } \\
\text { Bebas }\end{array}$ & $\begin{array}{c}\text { Jumlah } \\
\text { Kuadrat }\end{array}$ & $\begin{array}{c}\text { Kuadrat } \\
\text { Tengah }\end{array}$ & $\boldsymbol{F}$ & P-Value \\
\hline BAP & 3 & 1197.187 & 399.062 & 124.910 & 0.000 \\
\hline IAA & 3 & 2.566 & 0.855 & 0.268 & 0.848 \\
\hline $\begin{array}{l}\text { Interaksi BAP } \\
\text { dan IAA }\end{array}$ & 9 & 28.772 & 3.197 & 1.001 & 0.449 \\
\hline Kekeliruan & 64 & 204.468 & 3.195 & & \\
\hline Total & 79 & 2996.790 & & & \\
\hline
\end{tabular}

Dari hasil uji Anava pada tabel 9, dengan resiko kekeliruan 5\% dapat diketahui bahwa hanya konsentrasi zat pengatur tumbuh BAP yang signifikan sehingga dapat disimpulkan terdapat perbedaan pengaruh konsentrasi zat pengatur tumbuh BAP terhadap tinggi tanaman pada bunga krisan. Selanjutnya, melakukan uji perbandingan ganda menggunakan uji Duncan. Uji perbandingan ganda ini bertujuan untuk mengetahui konsentrasi zat pengatur tumbuh mana yang memberikan hasil optimal pada BAP untuk tinggi pada bunga krisan.

Tabel 10. Uji Duncan untuk Konsentrasi BAP

\begin{tabular}{|l|c|c|c|}
\hline \multirow{2}{*}{ Konsentrasi BAP } & \multirow{2}{*}{$\begin{array}{l}\text { Ukuran } \\
\text { Sampel }\end{array}$} & \multicolumn{2}{|c|}{ Subset } \\
\cline { 3 - 4 } & 20 & 1.910 & $\mathbf{2}$ \\
\hline $5 \mu \mathrm{M}$ & 20 & 2.325 & \\
\hline $2,5 \mu \mathrm{M}$ & 20 & 2.335 & \\
\hline $7,5 \mu \mathrm{M}$ & 20 & & 11.115 \\
\hline $0 \mu \mathrm{M}$ & & & \\
\hline
\end{tabular}


138 Ade Irma Nurwahidah, dkk.

Dari tabel 10 diatas konsentrasi BAP 2,5 $\mu \mathrm{M}, 5 \mu \mathrm{M}$, dan 7,5 $\mu \mathrm{M}$ memberikan pengaruh yang sama dan konsentrasi BAP $0 \mu \mathrm{M}$ meberikan pengaruh yang berbeda dengan konsentrasi BAP lainnya yaitu $2,5 \mu \mathrm{M}, 5 \mu \mathrm{M}$, dan $7,5 \mu \mathrm{M}$ terhadap tinggi pada bunga krisan. Dari hasil uji perbandingan ganda Duncan didapatkan konsentrasi zat pengatur tumbuh yang optimal terhadap tinggi bunga krisan yaitu konsentrasi BAP $0 \mu \mathrm{M}$.

\section{KESIMPULAN}

Pada pengujian anava untuk jumlah daun, jumlah tunas, dan tinggi hanya konsentrasi zat pengatur tumbuh BAP yang signifikan terhadap jumlah daun dan hasil uji perbandingan ganda Duncan didapatkan konsentrasi zat pengatur tumbuh yang optimal terhadap jumlah daun yaitu konsentrasi BAP 7,5 $\mu \mathrm{M}$, konsentrasi zat pengatur tumbuh yang optimal terhadap jumlah tunas yaitu konsentrasi BAP $5 \mu \mathrm{M}$, dan pada tinggi tanman konsentrasi BAP yang optimal yaitu $0 \mu \mathrm{M}$.

Pada pengujian anva untuk jumlah akar konsentrasi zat pengatur tumbuh BAP, IAA signifikan dan hasil uji interaksi antara BAP dan IAA signifikan terhadap jumlah akar pada bunga krisan. hasil uji perbandingan ganda Duncan didapatkan konsentrasi zat pengatur tumbuh yang baik terhadap jumlah akar yaitu konsentrasi BAP $0 \mu \mathrm{M}$ dan pada konsentrasi IAA yang memberikan hasil yang optimal yaitu pada konsentrasi $3 \mu \mathrm{M}$.

\section{DAFTAR PUSTAKA}

Lestari, Endang Gatri. 2008. Kultur Jaringan. Bogor. Akademia.

Montgomery, D.C. 2009. Design and Analysis of Experiments. Seventh Edition. New York. John Wiley $\&$ Sons Inc.

Sudjana. 2002. Desain dan Analisis Eksperimen. Edisi Ke-IV. Bandung. Tarsito. Suwanda. 2011. Desain Eksperimen untuk Penelitian Imiah. Bandung. Alfabeta. 